RESEARCH REPORT

\title{
Overweight and obesity and weight change in middle aged men: impact on cardiovascular disease and diabetes
}

\author{
S Goya Wannamethee, A Gerald Shaper, Mary Walker
}

J Epidemiol Community Health 2005;59:134-139. doi: 10.1136/jech.2003.015651

See end of article for authors' affiliations

Correspondence to: Dr S G Wannamethee, Department of Primary Care and Population Science, Royal Free and University College Medical School, Rowland Hill Street, London NW3 2PF

UK; goya@pcps.ucl.ac.uk

Accepted for publication 2 April 2004
Context: The benefit of weight reduction for cardiovascular disease (CVD) outcomes remains uncertain. Objective: To examine the effects of baseline body mass index on major CVD outcomes and diabetes over a 20 year follow up, and of weight change in the first five years over the subsequent 15 years.

Design and setting: A prospective study of British men followed up for 20 years.

Participants: Men aged 40-59 years with no diagnosis of CVD or diabetes ( $n=7176)$ of whom 6798 provided full information on weight change five years later.

Outcome measures: Major CVD events (fatal and non-fatal myocardial infarction and stroke, angina, "other" CVD deaths) and diabetes.

Results: During the 20 year follow up there were 1989 major CVD events and 449 incident cases of diabetes in the 7176 men. Risk of major CVD and diabetes increased significantly with increasing overweight and obesity. During the 15 year follow up, weight gain was associated with increased risk of CVD and diabetes. Weight loss was associated with lower risk of diabetes than the stable group irrespective of initial weight. No significant cardiovascular benefit was seen for weight loss in any men, except possibly in considerably overweight (BMI $27.5-29.9 \mathrm{~kg} / \mathrm{m}^{2}$ ) younger middle aged men $(R R=0.42$; $95 \% \mathrm{Cl} 0.22$ to 0.81 ).

Conclusion: Long term risk of CVD and diabetes increased significantly with increasing overweight and obesity. Weight loss was associated with significant reduction in risk of diabetes but not CVD, except possibly in considerably overweight younger men. Duration and severity of obesity seem to limit the cardiovascular benefits of weight reduction in older men.
O besity is associated with increased risk of coronary heart disease, hypertension, angina, stroke, and diabetes and constitutes an important cardiovascular health burden. ${ }^{12}$ Although most studies have shown weight reduction to be associated with a significant improvement in cardiovascular (CV) risk factors, ${ }^{3-8}$ the benefit of weight reduction on CV outcome is uncertain. ${ }^{9}$ While both prospective and intervention studies have shown weight loss to be associated with a significant reduction in diabetes, ${ }^{10}{ }^{13}$ most studies have failed to show any benefit for CV disease mortality or coronary disease outcome ${ }^{914-18}$ and one overview has even suggested an increased risk of cardiovascular disease (CVD) or coronary heart disease (CHD) with weight loss. ${ }^{9}$ Our earlier reports on weight change in middle aged men have shown significant reduction in risk of diabetes ${ }^{10}$ but no benefit for CHD events (myocardial infarction and CHD deaths $)^{14}$ or total mortality. ${ }^{19-21}$ In this report, we examine the long term effect of BMI and the effect of weight change on major CV related morbidity and mortality using a wider range of CVD outcomes, now including stroke and angina, and using the recent National Institutes of Health and WHO recommended BMI guidelines for overweight $\left(25.0-29.9 \mathrm{~kg} / \mathrm{m}^{2}\right)$ and obesity $\left(\geqslant 30 \mathrm{~kg} / \mathrm{m}^{2}\right) .^{322}$ A combined end point (heart attacks, stroke, angina, diabetes, or CVD deaths) was also used to assess whether weight loss was associated with benefit overall in risk of CV related morbidity and mortality. We also examine whether the effects of weight change are dependent on initial BMI.

\section{METHODS}

The British regional heart study is a prospective study of cardiovascular disease in 7735 men aged 40-59 years selected from age-sex registers of one general practice in each of 24 towns in England, Wales, and Scotland. The criteria for selecting the town, the general practice, and the subjects as well as the methods of data collection, have been reported. ${ }^{23}$ Research nurses administered to each man a standard questionnaire $(\mathrm{Q} 1 ; 1978-80)$ including questions on smoking habits, alcohol intake, physical activity, and medical history. Details of classification methods for smoking status, social class, physical activity, and body mass index have been reported. ${ }^{23}{ }^{24}$ Physical measurements were made and nonfasting blood samples taken. Five years after screening, a postal questionnaire similar to that administered at screening, was sent to all surviving men and detailed information obtained on changes in smoking behaviour, body weight, and other risk factors (Q5;1983-85). Ninety eight per cent of the survivors responded ( 7275 men) and 7100 provided information on weight change.

\section{Body mass index (BMI)}

Weight and height were measured at screening and BMI calculated as weight/height ${ }^{2}$. Five years later (Q5), the men stated their weight and BMI was calculated for each man based on reported weight and on measured height at screening. Men were divided into four BMI groups: normal weight $\left(<25 \mathrm{~kg} / \mathrm{m}^{2}\right)$, moderately overweight $(25.0-27.4 \mathrm{~kg} /$ $\left.\mathrm{m}^{2}\right)$, considerably overweight $\left(27.5-29.9 \mathrm{~kg} / \mathrm{m}^{2}\right)$, and obese $\left(\geqslant 30 \mathrm{~kg} / \mathrm{m}^{2}\right)$. Data on BMI at baseline were missing in three men. In a subgroup of 4252 men who attended for reexamination 20 years after initial screening (1998-2000), measured weight correlated highly with reported weight $(r=0.98)^{25}$ with little difference in mean reported weight and mean measured weight (79.3 compared with $79.9 \mathrm{~kg}$ respectively).

Abbreviations: CHD, coronary heart disease; CVD, cardiovascular disease 


\section{Cigarette smoking}

The men were classified according to their current (Q1) smoking status: never smoked, ex-cigarette smokers, and current smokers at four levels (1-19, 20,21-39, and $\geqslant 40$ cigarettes/day). In the analysis involving weight change Q1 to Q5, smoking categories were derived from the combined information at screening (Q1) and five years later (Q5). The men were classified as: never smoked, ex-smokers at both Q1 and Q5, recent ex-smokers (smokers at Q1, non-smokers at Q5), and current smokers ( $1-19$ and $\geqslant 20 /$ day).

\section{Pre-existing ischaemic heart disease and stroke}

At screening and at Q5 the men were asked whether a doctor had ever told them that they had angina or myocardial infarction (heart attack, coronary thrombosis), stroke, and a number of other disorders. The WHO (Rose) chest pain questionnaire was administered at the initial examination and a three orthogonal lead electrocardiogram recorded at rest. Men with evidence of CHD were defined as those with a recall of diagnosis of angina or heart attack made by a doctor, a response on WHO (Rose) chest pain questionnaire indicating angina or possible myocardial infarction, or electrocardiographic evidence of definite or possible myocardial ischaemia or myocardial infarction. ${ }^{26}$ Men with evidence of CHD but without recall of a doctor diagnosis of CHD are referred to as " undiagnosed CHD".

\section{Measures of weight change}

The percentage change in body weight between screening and Q5 was determined for each man. ${ }^{19}$ For a man of average height $(1.73 \mathrm{~m})$ in this study, a loss of $3 \mathrm{~kg}(4 \%)$ in weight constituted weight loss. ${ }^{19}$ Those who had gained or lost less than $4 \%$ in body weight were classified as stable. The men were grouped into four weight change categories: (a) weight loss, (b) stable, (c) "moderate" gain of $4 \%-10 \%$, and (d) "substantial" gain of $>10 \%$.

\section{Follow up}

All men have been followed up for all cause mortality, cardiovascular morbidity, and development of type 2 diabetes from the initial screening in January 1978-July 1980 to June 2000, a mean period of 21.3 years (range $20-22.5$ years) with follow up achieved for $99 \%$ of the cohort. ${ }^{27}$ This analysis is based on a 20 year follow up for each man. All men with recall of a doctor diagnosis of CHD, stroke, or diabetes at screening have been excluded from the analysis $(n=556)$. Information on death was collected through the established "tagging" procedures provided by the NHS registers. Evidence regarding non-fatal heart attacks, angina and strokes, and diabetes were obtained by reports from general practitioners, by biennial reviews of the patients' notes (including hospital and clinic correspondence) to the end of the study period, and from personal questionnaires to surviving subjects at the 5th year and 12-14th year after initial examination. Non-fatal stroke events were those that produced a neurological deficit present for more than 24 hours. A non-fatal heart attack was diagnosed according to WHO criteria. ${ }^{28}$ A diagnosis of diabetes was not accepted on the basis of self completed questionnaire data unless confirmed in the primary care records. ${ }^{11}$ In the analyses a combined end point is used, defined as death from any CV cause or the confirmed development of heart attack, angina, stroke, or diabetes.

\section{Statistical methods}

Cox's proportional hazards $^{29}$ model was used to obtain the relative risks for the weight change groups and body mass index groups adjusted for age, smoking, body mass index, social class, physical activity, blood pressure, use of antihypertensive treatment, lung function, serum total cholesterol, and undiagnosed CHD. Age, BMI, blood pressure, and total cholesterol were fitted continuously. Time of follow up for major CVD events was defined as the time to development of the first non-fatal CVD event (heart attack, stroke, or angina) or death, and similarly for diabetes and the combined end point (heart attack, stroke, angina, or diabetes). To obtain greater statistical power in assessing the relation between weight change and risk of the end points, we have tested for linear trends. Linear trends were assessed fitting weight change as a continuous variable (negative values for weight loss and positive values for weight gain). The purpose was to determine the significance of the change in risk over the continuum from maximum weight loss to maximum weight gain. Similarly, tests for linear trends for BMI were assessed fitting BMI in its original continuous form.

\section{RESULTS}

During the 20 year follow up from initial screening there were 1042 incident cases of major CHD events (non-fatal and fatal, 8.3/1000 person years), 395 stroke events (non-fatal and fatal, 3.1/1000 person years), 876 angina (7.1/1000 person years), 100 "other" CVD deaths (0.8/1000 person years), and 449 incident diabetes cases (3.5 rate/1000 person years) in the 7176 men with no history of CVD or diabetes. Altogether 1989 men had developed at least one major CVD end point (MI, angina, or stroke). A total of 173 men had

Table 1 Twenty year follow up in 7176 men, showing BMI $\left(\mathrm{kg} / \mathrm{m}^{2}\right)$ at screening $(\mathrm{Q} 1)$ and risk of major CVD events and diabetes (rates/1000 person years and adjusted (+) relative risk). (+) Adjusted for age, social class, smoking, physical activity, alcohol intake, undiagnosed CHD, and lung function

\begin{tabular}{|c|c|c|c|c|c|}
\hline & $\begin{array}{l}\text { Normal }<25 \\
(3313)\end{array}$ & $\begin{array}{l}\text { Moderately overweight } \\
25-27.5 \\
(2192)\end{array}$ & $\begin{array}{l}\text { Considerably overweight } \\
27.5-29.9 \\
(1104)\end{array}$ & $\begin{array}{l}\text { Obese } \geqslant 30 \\
(567)\end{array}$ & Test for linear trend* \\
\hline \multicolumn{6}{|l|}{ Major CVD (1989) } \\
\hline Number of cases & 786 & 621 & 364 & 218 & \\
\hline Rates $/ 1000$ person years & 13.9 & 17.2 & 20.2 & 24.9 & \\
\hline Adjusted (+) & 1.00 & 1.24 (1.11 to 1.38$)$ & $1.41(1.24$ to 1.60$)$ & 1.78 (1.52 to 2.08$)$ & $p<0.0001$ \\
\hline$+\mathrm{SBP}$ & 1.00 & $1.16(1.04$ to 1.30$)$ & 1.29 (1.14 to 1.49$)$ & 1.50 (1.28 to 1.75$)$ & $p<0.0001$ \\
\hline+ SBP+chol & 1.00 & 1.11 (0.99 to 1.23$)$ & $1.23(1.08$ to 1.40$)$ & $1.41(1.20$ to 1.65$)$ & $p<0.0001$ \\
\hline \multicolumn{6}{|l|}{ Diabetes (449) } \\
\hline Number of cases & 95 & 135 & 114 & 105 & \\
\hline Rates/ 1000 person years & 1.6 & 3.5 & 5.9 & 11.4 & \\
\hline Adjusted (+) & 1.00 & 2.41 (1.84 to 3.17$)$ & $4.00(3.02$ to 5.30$)$ & $7.49(5.59$ to 10.00$)$ & $p<0.0001$ \\
\hline$+\mathrm{SBP}$ & 1.00 & 2.27 (1.73 to 2.98$)$ & 3.64 (2.74 to 4.83$)$ & $6.30(4.67$ to 8.51$)$ & $p<0.0001$ \\
\hline$+\mathrm{SBP}+$ chol & 1.00 & $2.24(1.71$ to 2.94$)$ & $3.57(2.68$ to 4.74$)$ & 6.20 (4.58 to 8.38$)$ & $p<0.0001$ \\
\hline
\end{tabular}


Table 2 Weight change over five years (Q1 to Q5) and relative risk (RR) of major CVD and diabetes during 15 years of follow up in 6194 men. (+) Adjusted for age, social class, smoking, physical activity, alcohol intake, antihypertensive treatment, undiagnosed $\mathrm{CHD}_{1} \mathrm{FEV}_{1}$, systolic blood pressure, total cholesterol, and initial BMI

\begin{tabular}{|c|c|c|c|c|c|}
\hline & $\begin{array}{l}\text { Loss } \\
(782)\end{array}$ & $\begin{array}{l}\text { Stable } \\
(3499)\end{array}$ & $\begin{array}{l}\text { Moderate gain (4\%-10\%) } \\
\text { (1516) }\end{array}$ & $\begin{array}{l}\text { Substantial gain (>10\%) } \\
(397)\end{array}$ & $\begin{array}{l}\text { Test for linear } \\
\text { trend* }\end{array}$ \\
\hline \multicolumn{6}{|l|}{ Major CVD (1454) } \\
\hline Number of cases & 214 & 782 & 350 & 108 & \\
\hline Rates/1000 person years & 23.2 & 17.7 & 18.2 & 22.2 & \\
\hline Age adjusted RR & $1.30(1.12$ to 1.51$)$ & 1.00 & $1.06(0.93$ to 1.20$)$ & 1.29 (1.05 to 1.57$)$ & $p=0.76$ \\
\hline Adjusted RR (+) & $1.01(0.86$ to 1.18$)$ & 1.00 & 1.08 (0.95 to 1.23$)$ & 1.32 (1.07 to 1.62$)$ & $p=0.005$ \\
\hline \multicolumn{6}{|l|}{ Diabetes (327) } \\
\hline Number of cases & 39 & 172 & 87 & 29 & \\
\hline Rates/1000 person years & 3.9 & 3.6 & 4.2 & 5.6 & \\
\hline Age adjusted RR & 1.07 (0.76 to 1.52$)$ & 1.00 & $1.17(0.90$ to 1.51$)$ & 1.56 (1.05 to 2.31$)$ & $p=0.03$ \\
\hline Adjusted RR (+) & $0.62(0.42$ to 0.90$)$ & 1.00 & $1.26(0.97$ to 1.64$)$ & 1.76 (1.16 to 2.67$)$ & $p<0.0001$ \\
\hline
\end{tabular}

developed diabetes and a major CVD event, of whom 101 developed diabetes before a major CVD event.

Table 1 shows BMI at initial screening and risk of major CVD and diabetes adjusted first for age, social class, smoking, physical activity, alcohol intake, undiagnosed CH,D and lung function and then in addition for systolic blood pressure and total cholesterol. The strong positive relations with major CVD and diabetes are attenuated after adjustment for systolic blood pressure and further attenuated after additional adjustment for serum total cholesterol but the positive trends remain significant. Exclusion of the 101 men who developed diabetes before developing a major CVD event made little difference to the findings for CVD.

\section{Weight change and outcomes}

Of the 7176 men at baseline, data on weight change at Q5 were available on 6798 men. We further excluded all men with a recall of doctor diagnosis of CHD (MI, angina), stroke, or diabetes at Q5 and those with a major CVD event before Q5 based on the surveillance of GP records $(n=435)$, as well as men whose BMI decreased to $<18.5 \mathrm{~kg} / \mathrm{m}^{2}$ at Q5 as this weight is considered to indicate chronic ill health $(\mathrm{n}=169),{ }^{22}$ leaving 6194 men. Over the five years (Q1 to Q5), 57\% were stable in weight, $13 \%$ had lost weight, $24 \%$ had moderate weight gain $(4 \%-10 \%)$, and $16 \%$ had substantial weight gain $(>10 \%)$. In age adjusted analyses, weight loss was associated with a significant increase in risk of CVD but not of diabetes compared with the stable group ( $\mathrm{RR}=1.3095 \%$ CI 1.12 to $1.51 ; p=0.01$ ) (table 2). In previous reports, we have shown that initial weight is highest in those who lost weight and lowest in those who had gained weight. ${ }^{14}$ Weight change, in particular weight loss, has been shown to be associated with many of the cardiovascular risk factors including smoking, high blood pressure, total cholesterol, $\mathrm{FEV}_{1}$, physical inactivity, alcohol intake, and social class. ${ }^{14}$ Additional adjustment for initial BMI and these CV risk factors reduced the increased risk seen with weight loss for CVD and risk was similar to the stable group. After these adjustments weight loss was associated with a significant reduction in risk of diabetes compared with the stable group $(\mathrm{RR}=0.6295 \% \mathrm{CI}$ 0.42 to $0.90 ; p=0.01$ ). There was a tendency for risk of both CVD and diabetes to increase with increasing weight gain $(p=0.005$ and $p<0.0001$ for trend respectively). Risk of both CVD and diabetes was significantly increased with substantial weight gain $(\mathrm{RR}=1.3295 \% \mathrm{CI} 1.07$ to $1.62 ; \mathrm{p}<0.01$ and $\mathrm{RR}=1.7695 \%$ CI 1.16 to $2.67 ; \mathrm{p}<0.01$ respectively).

Table 3 Initial BMl and weight change categories (Q1 to Q5) showing mean BMl at Q1 and Q5, BMl categories at Q5 and mean cardiovascular risk factors (Q1) in 6194 men

\begin{tabular}{|c|c|c|c|c|c|c|c|c|c|}
\hline \multirow[b]{2}{*}{ Initial BMI $\left(\mathrm{kg} / \mathrm{m}^{2}\right)$} & \multirow[b]{2}{*}{ Number } & \multirow[b]{2}{*}{$\begin{array}{l}\text { Mean initial } \\
\text { BMI (Q1) }\end{array}$} & \multirow[b]{2}{*}{$\begin{array}{l}\text { Mean } \\
\text { BMI Q5 }\end{array}$} & \multicolumn{4}{|c|}{ BMI categories at Q5 } & \multirow[b]{2}{*}{$\begin{array}{l}\text { Mean } \\
\text { initial SBP }\end{array}$} & \multirow[b]{2}{*}{$\begin{array}{l}\text { Mean } \\
\text { initial cho }\end{array}$} \\
\hline & & & & \% Normal & $\begin{array}{l}\text { \% Moderately } \\
\text { overweight } \\
\text { (25-27.4) }\end{array}$ & $\begin{array}{l}\text { \% Considerably } \\
\text { overweight } \\
(27.5-29.9)\end{array}$ & $\%$ Obese & & \\
\hline \multicolumn{10}{|l|}{$<25$} \\
\hline Stable & 1546 & 23.1 & 23.2 & 92.8 & 7.8 & 0 & 0 & 139.8 & 6.16 \\
\hline Loss & 214 & 23.2 & 21.7 & 100 & 0 & 0 & 0 & 140.7 & 6.23 \\
\hline Gain (4\%-10\%) & 840 & 22.7 & 24.1 & 58.4 & 36.3 & 0 & 0 & 139.8 & 6.10 \\
\hline Gain (>10\%) & 281 & 22.1 & 25.3 & 0 & 42.7 & 40.9 & 15.0 & 139.5 & 6.00 \\
\hline \multicolumn{10}{|l|}{$25-27.5$} \\
\hline Stable & 1145 & 26.2 & 26.2 & 9.3 & 82.1 & 8.6 & 0 & 146.3 & 6.37 \\
\hline Loss & 251 & 26.2 & 24.4 & 72.1 & 27.9 & 0 & 0 & 147.2 & 6.48 \\
\hline Gain (4\%-10\%) & 435 & 26.1 & 27.7 & 0 & 43.2 & 56.6 & 0.2 & 143.8 & 6.37 \\
\hline Gain (>10\%) & 67 & 26.0 & 29.6 & 0 & 0 & 64.2 & 35.8 & 141.9 & 6.11 \\
\hline \multicolumn{10}{|l|}{$27.5-29.9$} \\
\hline Stable & 562 & 28.5 & 28.5 & 0 & 13.9 & 80.1 & 6.1 & 148.8 & 6.40 \\
\hline Loss & 188 & 28.6 & 26.3 & 11.7 & 71.8 & 16.5 & 0 & 152.0 & 6.41 \\
\hline Gain (4\%-10\%) & 161 & 28.6 & 30.4 & 0 & 0 & 35.4 & 64.6 & 147.7 & 6.30 \\
\hline Gain (>10\%) & 28 & 28.7 & 32.4 & 0 & 0 & 0 & 100 & 151.8 & 6.47 \\
\hline \multicolumn{10}{|l|}{$30+$} \\
\hline Stable & 231 & 31.8 & 31.8 & 0 & 0 & 10.3 & 89.7 & 154.7 & 6.51 \\
\hline Loss & 129 & 32.2 & 29.2 & 4.7 & 13.2 & 55.0 & 27.1 & 158.7 & 6.68 \\
\hline Gain (4\%-10\%) & 77 & 32.1 & 34.1 & 0 & 0 & 0 & 100 & 156.4 & 6.24 \\
\hline Gain (>10\%) & 21 & 32.6 & 37.2 & 0 & 0 & 0 & 100 & 152.4 & 6.13 \\
\hline
\end{tabular}


Table 4 Fifteen year follow up in 6194 men with adjusted relative risks (95\% CI) for major CVD events, diabetes, and the combined end point according to initial BMI and weight change categories over five years (Q1 to Q5). Adjusted for age, social class, smoking, physical activity, alcohol intake, antihypertensive treatment, undiagnosed $\mathrm{CHD}, \mathrm{FEV}_{1}$, systolic blood pressure, and total cholesterol

\begin{tabular}{|c|c|c|c|c|c|c|}
\hline & $\begin{array}{l}\text { Number } \\
\text { of cases }\end{array}$ & Loss & Stable & Moderate gain $4 \%-10 \%$ & Substantial gain $>10 \%$ & $\begin{array}{l}\text { p Value } \\
\text { linear trend } \neq\end{array}$ \\
\hline \multicolumn{7}{|l|}{ Major CVD } \\
\hline$<25$ & 584 & 1.12 (0.89 to 1.63$)$ & 1.00 & $1.28(1.06 \text { to } 1.55)^{*}$ & $1.32(0.99$ to 1.76$) \dagger$ & 0.008 \\
\hline $25-27.5$ & 447 & 0.90 (0.67 to 1.20$)$ & 1.00 & 0.93 (0.73 to 1.18 ) & $1.71(1.10 \text { to } 2.66)^{*}$ & 0.25 \\
\hline $27.5-29.9$ & 276 & $0.78(0.56$ to 1.08$)$ & 1.00 & 0.90 (0.64 to 1.28$)$ & 1.54 (0.84 to 2.84$)$ & 0.09 \\
\hline$\geqslant 30$ & 147 & $1.25(0.83$ to 1.86$)$ & 1.00 & 0.93 (0.57 to 1.51$)$ & $0.81(0.34$ to 1.94$)$ & 0.54 \\
\hline \multicolumn{7}{|l|}{ Diabetes } \\
\hline$<25$ & 72 & $0.42(0.10$ to 1.74$)$ & 1.00 & 0.97 (0.54 to 1.73$)$ & $2.02(0.96$ to 4.25$) \dagger$ & 0.005 \\
\hline $25-27.5$ & 99 & $0.88(0.43$ to 1.82$)$ & 1.00 & $1.75(1.10 \text { to } 2.76)^{*}$ & $2.24(0.99$ to 5.07$) \dagger$ & 0.03 \\
\hline $27.5-29.9$ & 83 & 0.63 (0.33 to 1.21$)$ & 1.00 & $1.15(0.66$ to 2.01$)$ & $0.93(0.28$ to 3.08$)$ & 0.04 \\
\hline$\geqslant 30$ & 73 & $0.52(0.25$ to 1.07$) \dagger$ & 1.00 & 1.40 (0.76 to 2.57$)$ & $2.55(1.04 \text { to } 6.29)^{*}$ & 0.005 \\
\hline \multicolumn{7}{|c|}{ Combined end point } \\
\hline$<25$ & 636 & $1.12(0.83$ to 1.52$)$ & 1.00 & $1.22(1.02 \text { to } 1.47)^{*}$ & $1.35(1.03 \text { to } 1.77)^{*}$ & 0.001 \\
\hline $25-27.5$ & 514 & 0.92 (0.70 to 1.22$)$ & 1.00 & $1.06(0.85$ to 1.30$)$ & $1.78(1.19 \text { to } 2.68)^{*}$ & 0.08 \\
\hline $27.5-29.9$ & 334 & $0.77(0.57$ to 1.04$) \dagger$ & 1.00 & $0.98(0.73$ to 1.33$)$ & $1.54(0.89$ to 2.67$)$ & 0.01 \\
\hline$\geqslant 30$ & 199 & 1.01 (0.70 to 1.46$)$ & 1.00 & $1.10(0.74$ to 1.66$)$ & 1.46 (0.79 to 2.70$)$ & 0.10 \\
\hline
\end{tabular}

Significantly/marginally significantly different from stable group, ${ }^{*} \mathrm{p}<0.05 ; \uparrow 0.05<\mathrm{p}<0.09$. $\ddagger$ Test for linear trend with weight change fitted as a continuous variable.

\section{Initial BMI and weight change}

Table 3 shows the mean BMI at Q1 and at Q5, the distribution of BMI categories at Q5, and mean systolic blood pressure and total cholesterol by initial BMI and weight change categories. Almost $40 \%$ of normal weight men gained weight over five years and all those who gained substantial weight became overweight or obese. Most obese men who lost weight remained overweight or obese $(82 \%)$. Most of the considerably overweight men who gained weight became obese. Mean systolic blood pressure and total cholesterol rose progressively with increasing levels of initial BMI. Men who lost weight, irrespective of their initial BMI, tended to have higher systolic blood pressure and higher serum total cholesterol concentrations at baseline than those who were stable or gained weight.

\section{Weight change and risk}

Table 4 shows the adjusted relative risk within initial BMI groups according to weight change categories. Weight loss was associated with a reduction in risk of diabetes within all BMI categories. In these men, a test for linear trend from maximum weight loss to maximum weight gain was significant in each BMI category. Weight loss showed some benefit for major CVD events in the considerably overweight men (BMI $27.5-29.9 \mathrm{~kg} / \mathrm{m}^{2}$ ) compared with the stable group, although in the small number involved the difference was not statistically significant. In the combined end point, these considerably overweight men showed marginally significantly lower risk than the stable group $(\mathrm{RR}=0.7795 \% \mathrm{CI}$ 0.57 to $1.04 ; \mathrm{p}<0.09$ ) and the test for trend was significant (linear trend $\mathrm{p}=0.01$ ). Compared with the stable group,

Table 5 Fifteen year follow up in 6194 men with adjusted relative risks $(95 \% \mathrm{Cl})$ for major CVD events and the combined end point in two age groups according to initial BMl and weight change categories over five years (Q1 to Q5). Adjusted for age, social class, smoking, physical activity, alcohol intake, antihypertensive treatment, undiagnosed CHD, FEV 1 , systolic blood pressure, and total cholesterol

\begin{tabular}{|c|c|c|c|c|c|}
\hline & Number (cases) & Loss & Stable & Gain & $\begin{array}{l}\text { p Value } \\
\text { linear trend } \ddagger\end{array}$ \\
\hline \multicolumn{6}{|l|}{ Major CVD } \\
\hline \multicolumn{6}{|l|}{$40-49$ years } \\
\hline$<25$ & $1587(234)$ & $1.81(1.11 \text { to } 2.95)^{*}$ & 1.00 & $1.56(1.19 \text { to } 2.06)^{*}$ & 0.003 \\
\hline $25-27.4$ & $948(167)$ & $1.17(0.73$ to 1.89$)$ & 1.00 & $1.38(0.98$ to 1.94$) \dagger$ & 0.03 \\
\hline $27.5-29.9$ & 465 (116) & $0.42(0.22 \text { to } 0.81)^{* *}$ & 1.00 & $0.92(0.58$ to 1.44$)$ & 0.05 \\
\hline $30+$ & $230(62)$ & $0.93(0.49$ to 1.76$)$ & 1.00 & $0.90(0.45$ to 1.79$)$ & 0.88 \\
\hline \multicolumn{6}{|l|}{$50-59$ years } \\
\hline$<25$ & $1313(351)$ & 0.99 (0.66 to 1.47$)$ & 1.00 & 1.09 (0.87 to 1.37$)$ & 0.32 \\
\hline $25-27.4$ & $950(280)$ & $0.76(0.52$ to 1.11$)$ & 1.00 & $0.80(0.60$ to 1.09$)$ & 0.76 \\
\hline $27.5-29.9$ & $474(160)$ & 0.95 (0.64 to 1.42$)$ & 1.00 & $1.03(0.65$ to 1.61$)$ & 0.47 \\
\hline $30+$ & $228(85)$ & $1.57(0.86$ to 2.85$)$ & 1.00 & $0.97(0.51$ to 1.84$)$ & 0.52 \\
\hline \multicolumn{6}{|c|}{$\begin{array}{l}\text { Combined end point } \\
40-49 \text { years }\end{array}$} \\
\hline$<25$ & $1587(261)$ & $1.65(1.03 \text { to } 2.65)^{*}$ & 1.00 & $1.48(1.13 \text { to } 1.94)^{* *}$ & 0.0005 \\
\hline $25-27.4$ & $948(204)$ & $1.19(0.77$ to 1.84$)$ & 1.00 & $1.61(1.18 \text { to } 2.19)^{\star *}$ & 0.003 \\
\hline $27.5-29.9$ & $465(156)$ & $0.55(0.32$ to 0.93$)$ * & 1.00 & $1.06(0.72$ to 1.57$)$ & 0.007 \\
\hline $30+$ & $230(98)$ & $0.87(0.51$ to 1.48$)$ & 1.00 & $1.13(0.68$ to 1.89$)$ & 0.09 \\
\hline \multicolumn{6}{|l|}{$50-59$ years } \\
\hline$<25$ & $1313(376)$ & $0.91(0.61$ to 1.35$)$ & 1.00 & $1.10(0.88$ to 1.38$)$ & 0.27 \\
\hline $25-27.4$ & $950(310)$ & $0.77(0.54$ to 1.11$)$ & 1.00 & 0.85 (0.64 to 1.19$)$ & 0.87 \\
\hline $27.5-29.9$ & $474(178)$ & $0.86(0.58$ to 1.26$)$ & 1.00 & $1.15(0.75$ to 1.76$)$ & 0.19 \\
\hline $30+$ & 228 (101) & $0.99(0.55$ to 1.79$)$ & 1.00 & $1.14(0.65$ to 1.98$)$ & 0.25 \\
\hline
\end{tabular}


moderate weight gain was associated with increased risk of the combined end point only in normal weight men $(\mathrm{RR}=1.2295 \%$ CI 1.02 to 1.47$)$. Substantial weight gain was associated with increased risk of the combined end point within all BMI categories although compared with the stable group this was significant only in the normal weight and moderately overweight groups $(\mathrm{p}<0.05)$ possibly because of the smaller numbers involved.

\section{Age and outcome}

Table 5 shows the relation between weight change and major CVD outcome and the combined end point by age group (4049 and 50-59 years). To retain sufficient numbers, the two weight gain groups (moderate and substantial) were combined. The benefit of weight loss on CVD in the considerably overweight men was only seen in the younger age group $(\mathrm{RR}=0.4295 \%$ CI 0.22 to $0.81 ; \mathrm{p}<0.01)$. No significant benefit was seen in older men. Although the numbers were small, weight loss was associated with benefit for diabetes in both age groups irrespective of initial BMI (data not shown). Weight loss showed little benefit for the combined end point except in the younger, considerably overweight men $(\mathrm{RR}=0.55$ 95\% CI 0.32 to $0.93 ; \mathrm{p}<0.01)$.

\section{DISCUSSION}

There has been debate as to whether BMI is an independent risk factor for CVD. ${ }^{30}$ In our earlier report on BMI and CHD based on eight years of follow up, no independent association was seen between BMI and risk of CHD after adjustment for blood pressure and total cholesterol. ${ }^{31}$ However, in this 20 year follow up study, and possibly reflecting the duration of obesity and its consequences, increasing BMI was associated with a progressive and significant increase in the adjusted risk of major CVD and diabetes even after additional adjustments for systolic blood pressure and total cholesterol. This is consistent with many other long term prospective studies. ${ }^{32-37}$ The effect of duration of obesity on outcome may contribute to the limited benefit commonly observed with weight reduction in prospective studies of overweight/obese middle aged or older men despite the improvement in their $\mathrm{CV}$ risk factors.

\section{Weight change and major CVD and diabetes}

Moderate weight reductions $(5 \%-10 \%)$ have been shown to be associated with an improvement in blood pressure, blood lipids, ${ }^{3-7}$ insulin sensitivity and glycolated haemoglobin, ${ }^{8}$ but most studies have shown no benefit of weight loss on CVD and some have even shown significantly increased risk of CVD. ${ }^{915-18}$ These paradoxical findings have aroused concern

\section{Key points}

- Risk of major CVD and diabetes increased significantly with increasing overweight and obesity.

- Substantial weight gain (>10\%) was associated with increased risk of CVD and diabetes.

- Weight loss was associated with reduction in risk of diabetes in all baseline BMI categories.

- Weight loss shows no benefit for CVD except possibly in considerably overweight (BMI $27.5-29.9 \mathrm{~kg} / \mathrm{m}^{2}$ ) younger middle aged men

- Most overweight or obese men, even those who lose weight, remain overweight or obese. Chronicity of overweight/obesity seems to limit the possible cardiovascular benefits of weight reduction. regarding recommendations for weight loss in late adulthood. ${ }^{9}$ Most studies have focused on CV or CHD mortality as an end point or specifically on heart attacks. The impact of obesity on morbidity has been shown to be higher than the impact on mortality, ${ }^{38}$ and thus artefacts resulting from reverse causation - that is, weight loss as a result of illness leading to death-are likely to be less of a problem in studies on the incidence of CVD than in studies on death alone. ${ }^{39}$ In this study, using a range of end points including CV mortality and morbidity (heart attacks, angina, and stroke), there was no benefit of weight reduction on major CVD outcome but a significant reduction in diabetes risk. The association between weight loss and CVD seems to be to some extent dependent on initial BMI. Benefit of weight loss on CVD was only seen in considerably overweight younger middle aged men. Among normal weight, moderately overweight, and obese men no benefit was seen. In all men risk of major CVD tended to increase with increasing weight gain. Moderate weight gain showed no effect on the relative risk of CVD compared with stable weight men except in normal weight men. However, substantial weight gain $(>10 \%)$ was associated with increased risk in both normal weight and in moderately and considerably overweight men although this was only significant/marginally significant in normal weight and moderately overweight men possibly because of the small numbers. This study confirms the significant benefits of weight reduction on risk of diabetes, particularly in obese subjects, which is consistent with results from other observational and intervention studies..$^{10-13}{ }^{40}$ Overall in all men, weight gain was associated with increased risk of diabetes.

\section{Age and weight loss}

The benefit of weight loss on CVD in considerably overweight men was only significant in the younger men (40-49 years). These findings are in keeping with those from the Honolulu heart study in which weight loss in men $<55$ years was associated with lower risk of CHD (albeit non-significant) than those with stable weight, whereas weight loss after age 55 was associated with increased risk. ${ }^{15}$ It is suggested that weight loss in younger adults primarily reflects changes in body fat, whereas weight loss in older subjects may be attributable to decrease in fat mass or lean body mass or underlying disease. ${ }^{41-42}$ This may partly explain the lack of benefit for CVD in the considerably overweight older subjects in this cohort. As morbidity increases with age, the increased risk seen with weight loss in older age often reflects underlying ill health leading to weight loss.

\section{Obesity and weight loss}

Although a noticeable reduction in risk of diabetes was seen in obese men who lost weight, little benefit was seen for CVD outcome in these men. This may be because most obese men who lost weight remained obese or considerably overweight (average BMI $29.0 \mathrm{~kg} / \mathrm{m}^{2}$ ) and examination of BMI in these men seven to nine years after their weight loss showed that most of these men had regained weight. Obese men who reported weight loss had much higher mean initial blood pressure and higher initial total cholesterol levels than obese men with stable weight. Those with diagnosed severe hypertension or diagnosed hypercholesterolaemia may be more motivated to reduce weight or may lose weight more easily because of pre-clinical disease. We do not have information on whether weight loss is intentional or unintentional but a previous cross sectional report from this study showed that weight loss, whether intentional or unintentional, was associated with a greater prevalence of CVD related disorders. ${ }^{43}$ It is probable that many of the obese men will have been advised to lose weight for health reasons. 
Despite their weight loss, these obese men remained overweight or obese, they are unlikely to have significantly improved their blood pressure and blood lipids profiles and many will already have developed end organ damage. The benefits of weight reduction seen for diabetes but not CVD may be because the cardiovascular damage is well established and cannot readily be regressed while for diabetes, the change in insulin resistance consequent upon reduction in the amount of body fat may be sufficient to reduce the risk of diabetes.

\section{Conclusion}

In this 20 year follow up of middle aged men, overweight/ obesity is associated with a significant increase in risk of major CVD and diabetes even after additional adjustment for systolic blood pressure and total cholesterol. Weight loss is associated with a significant reduction in risk of diabetes for all men but benefit for major CVD events was only seen in considerably overweight younger subjects. The chronicity of obesity and its consequences seem to limit the benefit of weight reduction for major CVD outcome. Our findings provide evidence supporting the benefits of weight reduction in overweight/obese men ${ }^{3}$ and suggest that the younger the age at intervention the greater the probable benefit. While prevention of overweight/obesity remains a key objective the development of effective strategies to help middle aged overweight/obese subjects to lose weight and to maintain or improve the achieved weight loss, is currently a critical need.

\section{ACKNOWLEDGEMENTS}

The British regional heart study is a British Heart Foundation Research Group and receives support from the Department of Health (England). The views expressed in this publication are those of the authors and not necessarily those of the Department of Health (England).

\section{Authors' affiliations}

S G Wannamethee, A G Shaper, M Walker, Department of Primary Care and Population Science, Royal Free and University College Medical School, London, UK

Funding: none.

Conflicts of interest: none declared.

\section{REFERENCES}

1 British Nutrition Foundation's Task Force. Obesity. Oxford, UK: Blackwell Science, 1999.

2 National Task Force on the Prevention and Treatment of Obesity. Overweight, obesity and health risk. Arch Intern Med 2000;160:898-904.

3 Expert panel. Clinical guidelines on the identification, evaluation, and treatment of overweight and obesity in adults: executive summary. Am J Clin Nutr 1998:68:899-917.

4 Wood PD, Stefanick ML, Williams PT, et al. The effects on plasma lipoproteins of a prudent weight-reducing diet, with or without exercise, in overweight men and women. N Engl J Med 1991;325:461-6.

5 Trials of Hypertension Prevention (TOHP) Collaborative Research Group. The effects of nonpharmacological interventions on blood pressure of persons with high normal levels. JAMA 1992;267:1213-20.

6 Goldstein DJ. Beneficial health effects of modest weight loss. Int J Obes Relat Metab Disord 1992;16:397-415

7 Higgins M, D'Agostina R, Kannel W, et al. Benefits and adverse effects of weight loss. Observations from the Framingham study. Ann Intern Med 1993; 1 19:758-63.

8 Wing RR, Koeske R, Epstein $\mathrm{LH}$, et al. Long term effects of modest weight loss in type 2 diabetic patients. Arch Intern Med 1987;147:1749-53.

9 Lee I-Min. Is weight loss hazardous? Nutr Rev 1996;54(suppl III):116-24.

10 Colditz GA, Willett WC, Rotnitzsky A, et al. Weight gain as a risk factor for clinical diabetes mellitus in women. Ann Intern Med 1995; 122:481-6.

11 Wannamethee SG, Shaper AG. Weight change and duration of overweight and obesity in the incidence of type 2 diabetes. Diabetes Care 1999;22:1266-72.
12 Heymsfield SB, Segal KR, Hauptman J, et al. Effect of weight loss with Orlistat on glucose tolerance and progression to type 2 diabetes in obese adults. Arch Intern Med 2000;160:1321-6.

13 Sjostrom CD, Lissner L, Wedel H, et al. Reduction of incidence in diabetes, hypertension and lipid disturbances after intentional weight loss induced by bariatric surgery: the SOS intervention study. Obes Res 1999;7:477-84

14 Walker M, Wannamethee G, Shaper AG, et al. Weight change and risk of coronary heart disease in the British regional heart study. Int J Epidemiol 1995;24:694-703.

15 Galanis DJ, Harris T, Sharp DS, et al. Relative weight, weight change and risk of coronary heart disease in the Honolulu heart program. Am J Epidemiol 1998; 147:379-86.

16 Rosengren A, Wedel H, Wilhelmsen L. Body weight and weight gain during adult life in men in relation to coronary heart disease and mortality. Eur Heart $J$ 1999:20:269-77.

17 Dyer AR, Stamler J, Greenland P. Associations of weight change and weight variability with cardiovascular and all-cause mortality in the Chicago Western Electric Company study. Am J Epidemiol 2000;152:324-33.

18 Williamson DF, Pamuk E, Thun $M$, et al. Prospective study of intentional weight loss and mortality in overweight white men aged $40-64$ years. Am J Epidemiol $1999 ; 149: 491-503$

19 Wannamethee G, Shaper AG. Weight change in middle-aged British men: implications for health. Eur J Clin Nutr 1990;44:133-42.

20 Wannamethee SG, Shaper AG, Walker M. Weight change, body weight and mortality: the impact of smoking and ill health. Int J Epidemiol $2001 ; 30: 777-86$

21 Wannamethee SG, Shaper AG, Walker M. Weight change, weight fluctuation, and mortality. Arch Intern Med 2002;162:2575-80.

22 World Health Organisation. Report of a WHO consultation on obesity. Obesity: preventing and managing the global epidemic. Geneva: World Health Organisation, 1998

23 Shaper AG, Pocock SJ, Walker M, et al. British regional heart study: cardiovascular risk factors in middle-aged men in 24 towns. BMJ 1981;283:179-86.

24 Shaper AG, Wannamethee G, Weatherall R. Physical activity and ischaemic heart disease in middle-aged British men. Br Heart J 1991;66:384-94.

25 Thomas MC, Walker M, Lennon LT, et al. Non-attendance at re-examination 20 years after screening in the British regional heart study. J Public Health Med 2002;24:285-91.

26 Shaper AG, Cook DG, Walker M, et al. Prevalence of ischaemic heart disease in middle-aged British men. Br Heart J 1984;51:595-605.

27 Walker M, Shaper AG, Lennon L, et al. Twenty year follow-up of a cohor study based in general practices in 24 British towns. J Public Health Med 2000;22:479-85

28 Rose G, Blackburn H, Gillum RF, et al. Cardiovascular survey methods. 2d ed. Geneva: WHO, 1982.

29 Cox DR. Regression models and life tables. J R Stat Soc (B) 1972:34:187-220

30 Barrett-Connor EL. Obesity, atherosclerosis and coronary artery disease. Ann Intern Med 1985; 103:1010-19.

31 Shaper AG, Pocock SJ, Walker M, et al. Risk factors for ischemic heart disease: the prospective phase of the British regional heart study. J Epidemiol Community Health 1985;39:197-209.

32 Hubert HB, Feinleib M, McNamara PM, et al. Obesity as an independent risk factor for cardiovascular disease: a 26 year follow-up of participants in the Framingham heart study. Circulation 1983;67:968-77.

33 Wilson PWF, D'Agostino RB, Sullivan L, et al. Overweight and obesity as determinants of cardiovascular risk: the Framingham experience. Arch Intern Med 2002; 162:1867-72

34 Jonsson S, Hedblad B, Engstrom G, et al. Influence of obesity on cardiovascular risk. Twenty three year follow-up of 22025 men from an urban Swedish population. Int J Obes 2002;26:1046-53.

35 Wannamethee SG, Shaper AG, Whincup PH, et al. Role of risk factors for major coronary heart disease events with increasing length of follow up. Heart 1998;81:374-9.

36 Pekkanen J, Nissinen A, Puska P, et al. Does the predictive value of baseline coronary risk factors change over a 30 year follow-up. Cardiology 1993;82:181-90.

37 Jousilatahti $\mathbf{P}$, Tuomilehto J, Vartianinen $\mathrm{E}$, et al. Body weight, cardiovascular risk factors, and coronary mortality: 15 year follow-up of middle-aged men and women in Eastern Finland. Circulation 1996;93:1372-9.

38 Visscher TLS, Seidell JC. The public health impact of obesity. Annu Rev Public Health $2001 ; 22: 355-75$

39 Willett WC, Dietz WH, Colditz GA. Guidelines for healthy weight. N Engl J Med 1999:341:427-34

40 Tuomilehto J, Lindstrom J, Eriksson JG, et al. Prevention of type 2 diabetes mellitus by changes in lifestyle among subjects with impaired glucose tolerance. N Engl J Med 2001;344:1343-50.

41 Rimm EB, Stampfer MJ, Giovanucci E, et al. Body size and fat distribution as predictors of coronary heart disease among middle-aged and older US men. Am J Epidemiol 1995;141:1117-27.

42 Meltzer AA, Everhart JE. Unintentional weight loss in the United States. Am J Epidemiol 1995;142:1039-46.

43 Wannamethee SG, Shaper AG, Whincup PH, et al. Characteristics of older men who lose weight intentionally or unintentionally. Am J Epidemio $2000 ; 151: 667-75$ 